\title{
Theoretical consideration on creative tourism
}

Hiroyoshi Sano (Faculty of Economics, Kanazawa Seiryo University, hsano@seiryo-u.ac.jp)

\section{Abstract}

This study aims to examine the origins and the change of creative tourism concept through reviewing mainly previous studies. Creative tourism is new types of tourism, evolved as a new form of cultural tourism in the beginning of the 21th century, including the intention to make the negative impacts from cultural tourism as a new form of mass tourism diminish. In recent years, the focuses of creative tourism have changed from tourist behavior to the relationships between the tourist and the destinations. Recent concepts of creative tourism have been applied to a growing range of tourism, including tourism activities, the impacts of creative tourism for tourist destination and creative industries, planning and policy-making to improve tourist destination. Therefore, the framework for accelerating the practice of creative tourism is proposed by focusing on the relationship between tourism and creative industries, in reference to Landry's model 'the cycle of urban creativity'.
\end{abstract}

\section{Keywords}

creative tourism, sustainable tourism, cultural tourism, destination management organization, the cycle of urban creativity

\section{Introduction}

Over the decades, tourism has experienced continued growth to become one of the fastest growing economic sectors in the world. Japan has received much benefit from the growth of the tourism industry and the increase in number of inbound tourists. "Modern tourism is closely linked to development and encompasses a growing number of new destinations. Now, tourism is one of the phenomena in many countries that is the most important service industry. However, the rise of mass tourism also brought about several negative impacts of the natural and built environments, such as overcrowding, environmental problems, degradation of local culture, and so on. In the beginning of this century, various international conventions and declarations have put forward principles and guidelines for sustainable tourism to make all forms of tourism strive to be more sustainable. The World Tourism Organization proposed the definition of sustainable tourism as follows;

Sustainable tourism development guidelines and management practices are applicable to all forms of tourism in all types of destinations, including mass tourism and the various niche tourism segments. Sustainability principles refer to the environmental, economic and socio-cultural aspects of tourism development, and a suitable balance must be established between these three dimensions to guarantee its long-term sustainability. Thus, sustainable tourism should:

- Make optimal use of environmental resources that constitute a key element in tourism development, maintaining essential ecological processes and helping to conserve natural resources and biodiversity.

- Respect the socio-cultural authenticity of host communities, conserve their built and living cultural heritage and traditional values, and contribute to inter-cultural understanding and tolerance.
- Ensure viable, long-term economic operations, providing socio-economic benefits to all stakeholders that are fairly distributed, including stable employment and income-earning opportunities and social services to host communities, and contributing to poverty alleviation [WTO, 2005].

In the last few decades, the concept and practices of ecotourism have been rapidly developed in the whole world in terms of making the tourism featuring natural resources more sustainable. On the other hand, it seems that the researches and practices of socio-cultural aspects of sustainable tourism are insufficient, although cultural tourism has become one of the most developmental options for tourist destinations around the world. As the Organization for Economic Co-operation and Development (OECD) report noted, cultural tourism accounted for almost 360 million international tourism trips in 2007, or 40 per cent of global tourism [OECD, 2009]. In addition, the contribution of cultural tourism is even greater, since cultural tourists are estimated to spend as much as one-third more on average than other tourist [Richards, 2007]. However, growing numbers of tourists at major cultural sites and in small communities has raised questions about sustainability of this new form of mass tourism [Richards, 2013]. In the past, cultural tourism was often viewed as a good form of tourism, because of the small scale, high expenditure and low impact. Now, there is no doubt that cultural tourism is a major segment of global tourism. Against such a background, the concept of creative tourism was proposed as a new form of cultural tourism, intended to make the negative impacts of the tourism diminish as much as possible [Richards and Raymond, 2000].

This study aims to examine the concepts and possibility of creative tourism as a means of making cultural tourism more sustainable, mainly based on a review of literature. In addition, this study tries to consider the adaptive flexibility of creative tourism in Japan.

Creative tourism is defined by UNESCO as follows;

“travel directed toward an engaged and authentic experience, 
with participative learning in the arts, heritage, or special character of a place, and it provides a connection with those who reside in this place and create this living culture" [UNESCO, 2006].

Based on the definition above, this paper explores the origins and changes of the concept of creative tourism through previous papers, and proposes the framework for accelerating the practice of creative tourism.

\section{The origins and the change of the concepts of creative tourism}

Richards and Raymond explain creative tourism "offers visitors the opportunity to develop their creative potential through active participation in coursed and learning experiences which are characteristic of the holiday destination where they are undertaken" [Richards and Raymond, 2000]. Thus, early concepts of creative tourism were based on learning experiences related to traditional areas of culture and creativity. The concept of creative tourism mainly referred to the attitude of active tourists who are seeking learning experiences, often linked to elements of tangible culture, such as crafts. Richards explains the origins of the creative tourism concept as follows;

The roots of the Creative Tourism concept go back to the mid-1990s, when a group of researchers and practitioners were looking at ways to enhance the sales of craft products to tourists. The basic aim of the EUROTEX project was to help conserve craft production by marketing local products more effectively to tourists, developing new outlets for craft sales, and securing local jobs. It quickly became clear that one of the biggest challenges for craft producers was distinguishing their high value, handmade products from the cheaper mass-produced items. Unless the tourists can appreciate the work and skill that goes into making handcrafted products, they are unlikely to want to pay more for them.

Through discussions with craft producers and interviews with tourists, we quickly realised that many visitors were interested in seeing how craft products were to develop craft experiences which allowed the visitors to get involved with the production process, either by seeing craft producers at work or by learning particular textile production techniques. [Richards, 2010]

Richards writes that these basic ideas became the inspiration for what would later by called creative tourism. The early concept of creative tourism was a form of cultural tourism, based on the integration of cultural content into tourism.

\subsection{From cultural tourism to creative tourism}

Cultural tourism had long been considered as a niche market. But now, cultural tourism is widely seen as being one of the most important segments of global tourism. Cultural tourism is one of the oldest forms of special interest tourism. The World
Tourism Organization (UNWTO) defines cultural tourism as follows;

The movement of persons to cultural attractions in cities in countries other than their normal place of residence, with the intention to gather new information and experiences to satisfy their cultural needs and all movements of persons to specific cultural attractions, such as heritage sites, artistic and cultural manifestations, arts and drama to cities outside their normal country of residence [Whyte, Hood and White, 2012].

Cultural tourists give the places they visit benefit not only economically but culturally. The positioning of cultural tourism as a 'good' form of tourism which could deliver significant economic benefits partly explains its emergence as the 'fastest growing' and possibly largest segment of global tourism [Smith and Richards, 3p, 2013]. Therefore, many tourist destinations around the world have adopted the idea and the strategies of cultural tourism for attracting tourists. Culture has come to play an important role in distinguishing places from other destinations. Then, Richards and Wilson point out that one of the problems inherent in cultural distinction strategies is that many places adopt similar strategies (often copying or 'borrowing' ideas from one another), and therefore even 'culture' begins to lack distinction. The growth of 'serial reproduction' of culture epitomized by McGuggenheimization [Honigsbaum, 2001] and the spread of signature architecture to cities around the world makes it harder and more expensive to use material culture to distinguish places [Richards and Wilson, 2007]. In addition, Smith et al. point out that today's cultural tourist is just as likely to be in search of 'popular', 'everyday', 'low', 'street' culture as they are likely to visit a stuffy museum.

Although creative tourism has evolved from cultural tourism, it is not associated with the massive visitation of cultural attractions. Creative tourism focuses on acquiring authentic and creative experiences at the destination, mainly due to an active interaction between visitors and residents [Raymond, 2007]. Krajnovic and Gortan-Carlin explain the difference between cultural tourism and creative tourism that creative tourism is different from cultural, not only in the way of tourist activity taking place, but in values created for tourist consumers also. Top-quality creative tourism teaches tourists permanent skills. Creative tourism results in more than a material souvenir. Experience gained in creative tourism changes tourists in many ways. It gives him or her a mental souvenir possibly useful in everyday life, and also an experience changing his or her thinking about the surrounding world and his or her place in it. In other words, it gives him or her an experience which contributes to his or her own identity construction [Krajnovic and Gortan-Carlin, 2007]. Furthermore, OECD illustrates the change from cultural tourism, which is largely based on the resources of the past, towards creative tourism (Figure 1). The core assets of creative tourism are knowledge and skill-based, 


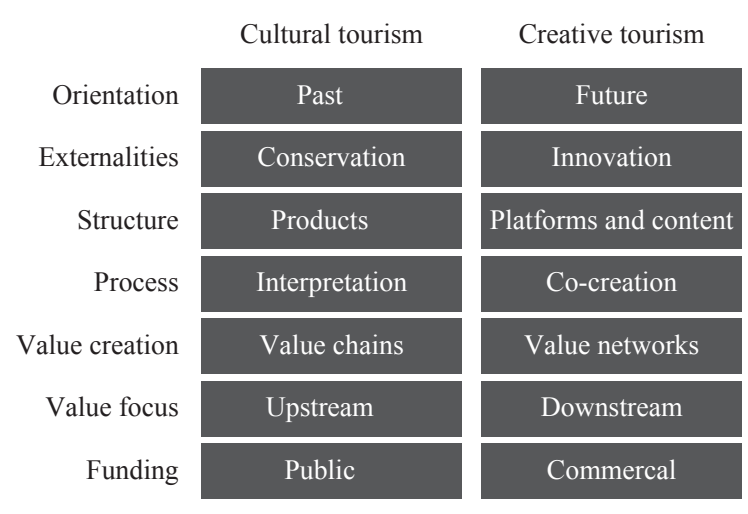

Figure 1: From cultural tourism to creative tourism Source: OECD (2014)

although the core assets of cultural tourism are largely related to built heritage. In cultural tourism approaches, much of the supply is managed or funded by the public sector, whereas creative tourism has a greater degree of commercial supply and participation [OECD, 2014]. More recently, Smith proposed three definitions of creative tourism, based on comparison with cultural tourism; the first implies going to the 'home' of a certain creative activity, whether it be crafts, dance, cookery or music, and engaging with local people and culture(s); the second definition means that visitors can undertake creative activities, but these may be in environments where the location is largely incidental and there is little or no contact with local people; third, creative tourism can involve the enjoyment of creative industries such as architecture, film, fashion or design. These industries often tend to be more globalized; therefore, the destination culture may or may not be an essential factor [Smith, 2016].

Thus, the concept of creative tourism has been strictly distinguished from cultural tourism as shown in the studies on creative tourism conducted recently. At the same time, recent concepts of creative tourism have been based on the integration of the tourism and creative industries as a whole, engaging not only tourists but also producers, policy makers and knowledge institutions. The concepts of creative tourism have been applied to a growing range of tourism activities, to include more passive forms of creativity, such as tasting experiences and shopping, as well as intangible forms of culture like media and lifestyle. The new features of creative tourism have important implications. This is now shifting towards a more extensive relationship between tourism and the creative industries, creative economy.

\subsection{Creative tourism in creative economy}

The creative industries are defined as; knowledge-based creative activities that link producers, consumers and places by utilizing technology, talent or skill to generate meaningful intangible cultural products, creative content and experiences [OECD, 14p, 2014]. The core sectors of the creative industries are identified as including; advertising, animation, architec- ture, design, film, games, gastronomy, music, performing arts, software and interactive games, television and radio, and so on. In many countries, the creative industries have grown faster than the economy as a whole, making them attractive to policy makers as drivers of sustainable economic growth and employment. The creative industries deliver a wide range of benefits, not only economically but also stimulating innovation, strengthening cultural identity and diversity, and developing linkages to tourism. In addition, creative industries help the urban innovation in western countries, in terms of strategic urban planning [Landry, 2000]. To compete successfully on the global stage, it is no longer enough to have culture, tourist destination has to have a cultural brand in order to compete [Evans, 2003]. The need to bundle and identify cultural resources led to the development of 'cultural quarters', 'cultural districts', 'creative clusters' or 'creative districts', where cultural and creative producers were clustered in order to generate a 'buzz'. In the creative economy, the focus is no longer on specific forms of culture but on creative content and the platforms that make the distribution of such content possible. On the other hand, tourism has shifted from an information-based paradigm [Poon, 2003] to a knowledge-based and skills-based paradigm, in which the skills and knowledge of the tourist also contribute to the tourism experience [Richards and Wilson, 2007]. This shift necessitates a more active role from producers, consumers and tourist destinations in the development, processing and distribution of knowledge and skill. Tourist destinations should understand not only what tourists want, but what the tourists can contribute to the destinations they visit.

Thus, at first the development of creative tourism was mainly focused on the creative activity of visitors, while today the creative environment in which the creative experience takes places is more centralized. Dekker and Tabbers pointed out that now a broader definition of the concept of creative tourism is formed. The ultimate goal is to let the tourist be part of the new surroundings of his or her destination. In other words, the tourist becomes part of the creative core of a destination [Dekker and Tabbers, 2012].

\subsection{Criticism of creativity in tourism}

Whereas most academics point out the need and the possibility of creative tourism, there are several criticisms of it. For instance, the use of creativity to develop tourism runs the risk of strengthening the tendency towards colonization of the lifeworld by the forces of commerce. In addition, the increasing contact with 'local' culture facilitated by creative tourism initiatives may also be problematic and whether one takes a critical or optimistic view of creative tourism initiatives therefore depends to a large extent on the intentions of the individual projects, and whether these succeed in delivering real benefits for local residents and indigenous creativity, the creative life of the destination or the creative experience of the tourist [Smith and Richards, 2013]. 


\section{Framework of creative tourism}

Linking tourism and the creative industries together in policy frameworks is a relatively new development and such linkages are not yet common. Awareness of the potential for growth and innovation through such linkages is low. There is therefore a need to develop integrated frameworks that can bring the different sectors together and support innovation. It is a fact that public sector leadership in this area is important, particularly in creating awareness. However, the bulk of the creative content and experience development is provided by the private sector; and both sectors are highly fragmented. Networking and cross-sectional linkages are therefore very important, and this may require the development of new governance models [OECD, 2014]. Therefore, this section proposes the framework of creative tourism, based on previous studies including criticism (Figure 2). Destination Management/Marketing Organization (DMO) is envisaged as a main organization for promoting the projects. The Japan Tourist Agency is now promoting the establishment of DMO across the country to increase competitiveness of tourist destinations and disseminate public-private partnership.

Landry proposed the 'cycle of urban creativity' as a dynamic concept, which attempts to create a form of urban energy that will drive a city like a renewable resource. The cycle can be thought of as five stages;

- Helping people generate ideas and projects

- Turning ideas into reality

- Networking, circulating and marketing ideas and projects

- Delivery mechanisms such as cheap spaces for rent, incubator units or exhibition and showcasing opportunities

- Disseminating results to the city, building markets and audi-

\section{ences and discussing these so that new ideas are generated}

The fifth stage then stimulates stage one to start over again [Landry, 2000]. This section proposed the framework of creative tourism based on the 'cycle of urban creativity' above.

\subsection{Generating ideas and projects: Stage one}

The starting point is the existence of creative ideas and ideas generation capacity in a tourist destination. Landry points out that this stage can be measured by the availability of patents, copyrights, brands or trademarks held by individuals, companies or associated with the city as well as the number of new businesses being set up, and the amount of people in the destination well known in their field. Even the general buzz and ambience is a measure as this encourages interaction.

The project of Kyushu Tourism Daigaku is a helpful example to put stage one into practice in Japan. Basically, Kyushu Tourism Daigaku is a project for the purpose of the development of human resources for rural tourism in Oguni-machi, Kumamoto prefecture, since 1997. Well known people in the industry of rural tourism, such as a professor, farmer, town official, accommodation manager, give a lecture every month from September to March. The students are approximately one-third local citizens and two-third outsiders. The important thing is the secondary effect caused by Kyushu Tourism Daigaku, that the buzz and ambience are generated through the dialogue between the students. In the result, a number of the ideas for utilizing local resources from the visitor's point of view have been brought to the town.

\subsection{Turning ideas into reality: Stage two}

Stage two asks whether there is enough capacity focused on

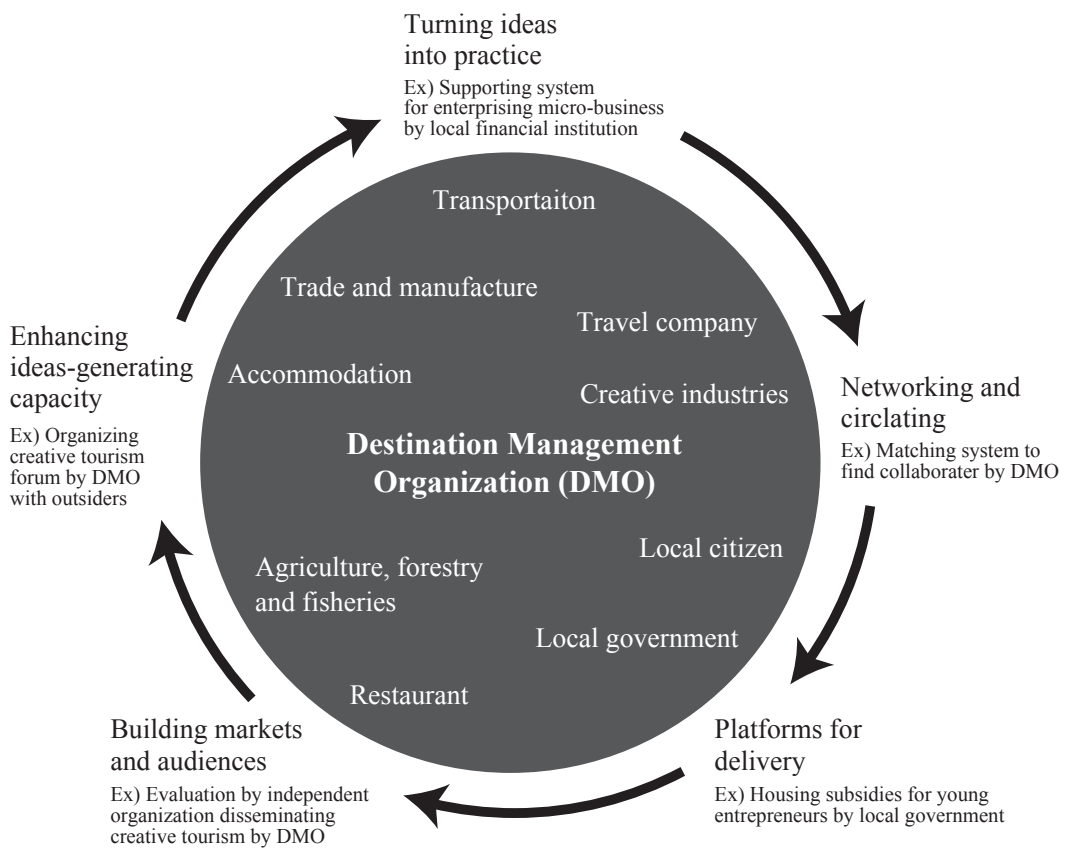

Figure 2: The framework of creative tourism 
turning ideas into practice. Therefore, the kinds of programs to provide active learning and business opportunities for young entrepreneurs and innovators in the creative industries would be needed. Landry explains that the conservatism of mainstream financial institutions, and the exclusion of new companies from resources to fund institutions, is one of the most serious impediments to the process of turning creativity into enterprise. Through links to some kinds of network for supporting entrepreneurs, it seeks to identify and build up a group of private investors who are interested in supporting innovative entrepreneurs through the injection of equity and expertise.

Local financial institutions are expected to support turning creative ideas into reality through various efforts, for example, support for business start-ups (loans, business start-up seminars), feasibility assessment service, assisting in developing proto-typing and market research. These endeavors would be necessary for nurturing prospective customers for them, and lead to future development of creative tourism.

\subsection{Networking, circulating and marketing ideas and prod- ucts: Stage three}

To make a tourist destination sustainable there need to be sufficient marketers, impresarios, managers, agencies, distributors, wholesalers, packagers and assemblers of tourism products and services. Landry points out that the challenge of this circulating phase is to get the myriad of potentially chaotic organizations into a creative milieu, to give them a sense of purpose and agency that will lead them to contribute to generating social capital, which in turn will benefit the destination as a whole. It has to draw on marketing techniques to develop the creative tourism vision and brand as a means of generating inspiration, involvement and commitment to the concept.

DMO would fulfill the role as a catalyst for future tie-ups between creators, as well as collaborations between creators and corporate businesses including local financial institutions, and a wide range of other partners including local governments and local citizens.

\subsection{Platforms for delivery: Stage four}

Creative people and projects need to be based and to sell their products and services somewhere. Creative tourism needs places, at the right price levels, in which to test ideas, pilot products, exhibit and sell work. A creative tourism destination requires land and buildings at affordable prices, which as a rule are in urban fringes or areas where patterns are changing, such as former downtown and historical zones. For example, the land prices are generally rising in so-called 'creative cities' such as Vancouver, Barcelona and Portland so that it is difficult for young entrepreneurs to settle down and start new business in such cities. Some kind of assistance such as housing subsidies are required for them.

DMO would be expected to fulfill the role as the platform for delivery as with stage three, for example, matching service between creators and real estate, operation of websites for promo- tion of creators, providing subsidies for renovation of historical buildings.

\subsection{Dissemination, reflection, evaluation: Stage five}

In the last stage, there are needs to debate engendering a response-positive or negative, and debate about creativity hitting all levels of the population. There are also needs to evaluate the project in terms of whether the projects of creative tourism brought negative impacts to the community.

DMO has to evaluate the projects in terms of creativity and would be required to take action based on the feedback for the next stage, for example, an international conference to review the projects, disclosure of information about the projects through the websites or book publishing to disseminate creative tourism practices.

\section{Consideration}

The concepts of creative tourism were evolved as a new form of cultural tourism in the beginning of the 21th century, including the intention to make the negative impacts of cultural tourism as a new form of mass tourism diminish and more sustainable, and were underlined with the tourist behavior such as active participation and learning experiences. As the studies on creative tourism have developed in recent years, their focuses have changed from tourist behavior to the relationships between the tourists and the destinations. Recent concepts of creative tourism have been applied to a growing range of tourism, including tourism activities, the impacts of creative tourism for tourist destination and creative industries, planning and policy-making to improve tourist destination. Therefore, the framework for accelerating the practice of creative tourism is proposed by focusing on the relationship between tourism and creative industries, in reference to the 'cycle of urban creativity'.

The expected results from the framework include increasing the number of creative contents and tourists, and enhancing the capability of DMO. Although creative tourism has been discussed for more than a decade, the integration of the concept within current frameworks has not been analyzed. In this sense, this paper aims to provide some thought about the fit of creative tourism activities in terms of the relationship between tourism and creative industries. Furthermore, this paper also identifies the areas where creative tourism may add value and increase the capability of DMO. This study points out the importance of creative tourism as a profit enhancing capability for the organization. It is expected that this framework of tourism may be used to increase the learning experience of the tourists. Therefore, it is also important that this framework be verified from the tourists and the local community perspectives. Further research needs to be carried out to understand in more detail how effective creative tourism is to accomplish these objectives.

\section{Acknowledgements}

This work was supported by JSPS KAKENHI Grant Num- 
ber 16K16677.

\section{References}

WTO (2005). Making tourism more sustainable: A guide for policy makers. World Tourism Organization.

OECD (2009). The impact of culture on tourism. OECD Publishing.

OECD (2014). Tourism and the creative economy, OECD studies on tourism. OECD Publishing.

Raymond, C. (2007). Creative tourism New Zealand: The practical challenges of developing creative tourism. In Richards G. and Wilson, J. (ed.) Tourism, creativity and development. Routledge.

Richards, G. and Raymond, C. (2000). Creative tourism. ATLAS News, Vol. 23, 16-20.

Richards, G. (ed.) (2007). Cultural tourism: Global and local perspectives. Haworth Press.

Richards, G. (2010). Creative tourism and local development, creative tourism: A global conversation.

Richards, G. (2013). Tourism development trajectories: From culture to creativity?. Melanie Smith and Greg Richards (ed.), The Routledge handbook of cultural tourism. Routledge.

Richards, G. and Wilson, J. (ed.)(2007). Tourism, creativity and development. Routledge.

UNESCO (2006). Towards sustainable strategies for creative tourism. Discussion report of the planning meeting for 2008 International Conference on Creative Tourism, http://unesdoc.unesco.org/images/0015/001598/159811E.pdf (Accessed on 23.10.2016)

Whyte, B., Hood, T., and White, B. (ed.) (2012). Cultural and heritage tourism: A handbook for community champions. Ottawa: Federal Provincial Territorial Ministers of Culture and Heritage.

Smith, M. and Richards, G. (2013). The Routledge handbook of cultural tourism. Routledge.

Krajnovic, A. and Gortan-Carlin, I. (2007). Possibilities of music heritage tourist valorization: An example of istria. Tourism and Hospitality Management, Vol. 13, No. 2.

Smith, M. (2016) Issues in cultural tourism studies. Routiedge.

Honigsbaum, M. (2001). McGuggenheim?, The guardian, 27. www. guardian.co.uk/saturday_review/story/0,3605,429259,00.html. (accessed October 23th 2016)

Evans, G. L. (2003). Hard branding the culture city: From Prado to Prada. International Journal of Urban and Regional Research, Vol. 27, No. 2, 417-440.

Landry, C. (2000). The creative city: A toolkit for urban innovation. Earthscan Publications.

Poon, A. (2003). A new tourism scenario - Key future trends: The Berlin report. Tourism Intelligence International, Vol. 21, No. 2, 214-232.

Dekker, T. and Tabbers, M. (2012). From creative crowds to creative tourism: A search for creative tourism in small and medium sized cities. Journal of Tourism Consumption and
Practice, Vol. 4, No. 2.

(Received November 8, 2016; accepted December 10, 2016) 